\title{
Interatividades na rede social Facebook entre docentes em processo de formação continuada
}

\author{
Interactions in the social networking Facebook between teachers in \\ education process
Interactivos en la red social Facebook entreprofesseurs en procedure de formation continue \\ Interactivos en la red social Facebook entre les profesores en proceso de \\ formación continua
}

\author{
Ana Paula Simões Pessoa ${ }^{1}$ \\ Maria Cristina Lima Paniago ${ }^{1}$
}

Recebido em 30/05/2017; revisado e aprovado em 18/07/2017; aceito em 25/07/2017

DOI: http://dx.doi.org/10.20435/inter.v19i2.1620

\begin{abstract}
Resumo: Este trabalho tem por objetivo analisar as possibilidades de interatividade entre professores em processo de formação continuada no contexto da rede social Facebook por meio das postagens realizadas em um grupo de professores. Será apresentada uma pesquisa qualiquantitativa, integrada a um grupo de pesquisa, o qual ofereceu uma formação continuada de professores, indígenas (na Aldeia Bananal, município de Aquidauana, MS) e não indígenas (de uma Universidade Privada), voltada para as discussões sobre as tecnologias no contexto educacional, com foco na interconectividade, linguagem e colaboração. Os resultados construídos ao longo da pesquisa mostram que abordagens distintas das atuais utilizadas nas postagens pelos membros do grupo podem ser desenvolvidas para que haja mais interação mútua e interatividade entre os participantes. Verificou-se também que o caminho para uma maior interatividade pode ser aprimorado com a participação-intervenção dos integrantes do grupo.
\end{abstract}

Palavras-chave: interatividade; Facebook; formação continuada de professores.

Abstract: This work analyzes the interactivity possibilities among teachers in teacher education process in the Facebook social network context by means of teachers' posts. A quali-quanti integrated research will be presented, associate to a research group which offered a teache course to indigenous teachers (in the Aldeia Bananal, municipality of Aquidauana, MS) and non-indigenous teachers (from a Private University focusing technologies on educational context, interconnectivity, language and collaboration). The results built up during the research show that different approaches to the present ones used in the postings by the group members can be developed so that there could be more mutual interaction and interactivity among the participants. It was also verified that the way to greater interactivity can be improved with the participationintervention of the group members.

Keywords: interactivity; Facebook; teachers course.

Résumé: Ce travail a pour objectif d'analyser les possibilités d'interactivités entre professeurs en procedure de formation continue dans le contexte du reseau social facebook à travers des publications réalisés dans le groupe. II sera presenté une étude quali-quantitative integré au groupe des études et des recherches en technologie educationel et éducation à distance, qui a offert une formation continue aux professeurs indigènes (Aldeia Bananal, municipalité Aquidauana, MS) et pas indigènes (université privé), retour dans les discussion sur les technologies dans le contexte educationel, avec pour cible l'interconectivite, langue et collaboration. Les resultats construits au long de la recherche montrent qu'aborder diverses actualités utilisés dans les postes des membres du groupe peuvent entrainer une hausse des interaction mutuels et des interactivités entre les participants. II a aussi été verifier que le chemin pour une meilleure activite pourrait-etre raffiné avec la participation et l'intervention des membres du groupes.

Mots-clés: interactivité; Facebook; formation continue de professeurs.

Resumen: Este trabajo tiene el objetivo de analizar las posibilidades de interactividad entre profesores en proceso de formación continua en el contexto de la red social Facebook por medio de las publicaciones realizadas en un grupo de profesores. Se trata de una investigación cuali-cuantitativa, integrada a un grupo

\footnotetext{
${ }^{1}$ Universidade Católica Dom Bosco (UCDB), Campo Grande, Mato Grosso do Sul, Brasil.
} 
de pesquisa, el cual ofreció una formación continua de profesores, indígenas (en la Aldea Bananal, municipio de Aquidauana, MS) y no indígenas (de una Universidad Particular), centrada en discusiones sobre las tecnologías en el contexto educacional, destacando la interconectividad, el lenguaje y la colaboración. Los resultados alcanzados a lo largo de la pesquisa muestran que se pueden abordar otros asuntos, diferentes de los actuales utilizados en las publicaciones de los miembros del grupo, para que haya más interacción mutua e interactividad entre los participantes. Se verificó también que el camino para una mayor interactividad puede ser mejorado con la participación-intervención de los integrantes del grupo.

Palabras clave: interactividad; Facebook; formación continua de profesores.

\section{INTRODUÇÃO}

Diante de realidades sempre novas e cada vez mais complexas, as formações de professores, tanto inicial como continuada, conforme aponta Kenski (2003), tentam explorar, as possibilidades fornecidas pelas Tecnologias de Informação e Comunicação (TIC), fazendo delas mais que um recurso para o processo de ensino e aprendizagem, mas também meio de formação e aprofundamento de conhecimentos, de reflexão e de desenvolvimento profissional contínuo. Por esse motivo, instiga-se problematizar e entender como tal fenômeno ocorre, pesquisando como a formação continuada se dá, se constitui, especialmente quando se desenvolve em ambientes virtuais, como, por exemplo, em rede social.

Este trabalho tem por objetivo analisar as possibilidades de interatividade entre professores em processo de formação continuada, no contexto da rede social Facebook, por meio das postagens realizadas em um grupo de professores presente nessa rede social.

Para atingir tal objetivo, optou-se por uma pesquisa qualiquantitativa, visto que também se verificou a participação dos integrantes do grupo por meio da análise numérica das postagens realizadas. Foram descritos os fluxos comunicacionais com enfoque na participação e intervenção nos processos interativos dos membros do grupo, isto é, se iniciam, continuam, problematizam, constroem ou descontroem questões postas nos diálogos com a finalidade de propiciar o estabelecimento de novas conexões.

O trabalho organiza-se em quatro partes: revisão de literatura, na qual se pode identificar o estado do conhecimento e a fundamentação teórica; metodologia, cujo modo de construção da pesquisa encontra-se detalhado; análise e resultados, com a descrição das conclusões obtidas por meio dos dados produzidos do grupo no Facebook; e considerações finais, com o fechamento e considerações a respeito do tema desta pesquisa.

\section{REVISÃO DE LITERATURA}

\subsection{As novas tecnologias de comunicação (TIC) e formação de professores: algumas possibilidades}

Segundo Bairral (2007), a formação de professores no contexto das novas tecnologias deve propiciar novidades no processo de aprendizagem, além de ir ao encontro com as condições que auxiliam as práticas docentes. Nessa acepção, Pierre Lévy (1999) complementa que o ambiente virtual caracteriza "não apenas a infraestrutura material da comunicação digital, mas também o universo oceânico de informações que ele abriga, assim como os seres humanos que navegam e alimentam esse universo" (LÉVY, 1999, p. 17).

Desse modo, faz-se necessário que os processos de formação abordem as questões tecnológicas voltadas à educação. Além disso, as formações docentes devem propiciar mudanças, 
visto que é fundamental para os professores "(re)aprender a conhecer, a comunicar, a ensinar; a integrar o humano e o tecnológico; a integrar o individual, o grupal e o social" (BRITO; PURIFICAÇÃO, 2008, p. 24). As tecnologias têm mudado o cotidiano da escola e os processos de ensino aprendizagem. Entretanto o interesse pelo seu uso na educação não é tão recente quanto pensamos. Valente (1999) afirma que, desde o final da década de 1960, as universidades brasileiras passaram a promover eventos para discutir sobre essas temáticas, como, por exemplo, a Primeira Conferência Nacional de Tecnologia em Educação Aplicada ao Ensino Superior (I CONTECE), realizada em 1971, no estado do Rio de Janeiro.

O campo da educação online aos poucos se expandiu, partilhando espaço a novas questões, possibilitando a inserção científica e tecnológica no país. Em 1981, houve o primeiro Seminário Nacional de Informática na educação, seguido pelo segundo, em 1982. Tais reuniões foram de suma importância para o processo de implantação da tecnologia na escola, visto que destacavam os benefícios tanto no campo do desenvolvimento da pesquisa, quanto no campo de recursos pedagógicos.

Em 1983, foi elaborado o Projeto Brasileiro de Informática na Educação (EDUCOM), o qual foi o primeiro projeto a abordar questões de informática educacional. De acordo com os autores mencionados acima, essa iniciativa foi relevante para a formação de pesquisadores e às ações que foram desenvolvidas posteriormente pelo Ministério da Educação e Cultura (MEC), como o projeto FORMAR, que fomentou cursos de especialização em informática na educação.

Como se pode perceber, a tecnologia adquiriu um papel significativo no campo educacional. Porém, algumas problemáticas surgiram no decorrer desse processo, como, por exemplo, o posicionamento dos professores frente às novas tecnologias, bem como a formação inicial e continuada desse docente. Segundo Kenski (2003), a formação inicial do professor, na grande maioria, é feita de modo mais tradicional, não sendo vivenciada a realidade das mídias para aprender. Nesse sentido:

Uma das soluções para esse impasse está na possibilidade de educadores também participarem das equipes produtoras dessas novas tecnologias educativas. Para isso é preciso que os cursos de formação de professores se preocupem em lhes garantir essas novas competências. Que ao lado do saber científico e do saber pedagógico, sejam oferecidas ao professor as condições para ser agente, produtor, operador e crítico dessas novas educações mediadas pelas tecnologias eletrônicas de comunicação e informação. (KENSKI, 2003, p. 49-50).

De acordo com Almeida (2000), a problemática abordada anteriormente se dá pelo fato de que os programas de formação são elaborados separadamente do contexto prático realizado nas instituições educacionais, e afirma ainda:

Embora ainda hoje muitos programas de preparação de professores sejam planejados a priori da prática pedagógica, não é mais possível se pensar a formação inicial como um conjunto de disciplinas que compõem uma grade curricular de cursos programados por especialistas, para serem oferecidos aos futuros professores - como é o caso da maioria dos cursos regulares de 20 grau, Magistério, graduação ou pós-graduação. Caso idêntico ocorre com os programas de atualização pedagógica e mesmo com os cursos de aperfeiçoamento ou outros oferecidos aos professores em exercício - que dizem ser de formação continuada, mas desconsideram o locus de desenvolvimento da prática pedagógica. (ALMEIDA, 2000, p. 45).

Sendo assim, tanto a formação inicial quanto a continuada devem estar baseadas em um processo de formação-ação, com o intuito de romper as barreiras do ensino tradicional, além 
de deixar clara a importância de compreender o aprender e o ensinar, fazendo com que esse profissional reflita sobre a própria prática docente.

A partir dessas colocações, as formações de professores voltadas para o uso das novas tecnologias de comunicação tentam partilhar as possibilidades da incorporação das TIC na educação, fazendo delas mais do que recurso didático para o processo de ensino e aprendizagem, mais sim um meio de formação e aprofundamento de conhecimentos, de reflexão e de desenvolvimento profissional contínuo.

\subsection{Interatividade na rede social Facebook}

Com o uso das tecnologias de informação e comunicação, concomitantemente os termos interação e interatividades são utilizados, com a finalidade de promover reflexões. Entretanto tais vocábulos possuem significados distintos, além de serem discutidos em diferentes perspectivas por vários autores. Dessa forma, Silva (2000) aponta a amplitude do conceito de interação, destacando três interpretações para esse termo: "uma genérica (a natureza é feita de interações físico-químicas ou, nenhuma ação humana existe separada da interação), uma mecanicista, linear (sistêmica) e uma marcada por motivações e predisposições (dialética, interacionista)" (SILVA, 2000, p. 103).

Para a realização desta pesquisa, destacamos a terceira interpretação posta por Silva (2000), a dialética e interacionista, pois ela possibilita a observação das experiências e diálogos colaborativos realizados por meio das TIC.

Outro conceito de interação que vai ao encontro do que foi exposto anteriormente, é o utilizado por Primo (2000). Esse autor aponta a necessidade das relações interpessoais para a ocorrência da interação. Além disso, ele destaca dois tipos de interação, a mútua, que atua no campo do diálogo recíproco entre os integrantes de um determinado grupo, e a reativa, a qual "se caracteriza por um sistema fechado" (PRIMO, 2000, p. 89), isto é, as respostas e relações entre os indivíduos são previamente determinadas pelo sistema.

Para Silva, interatividade está na "disposição ou predisposição para mais interação, para uma hiper-interação, para bidirecionalidade- fusão emissão-recepção-, para participação e intervenção" (SILVA, 1998, p. 29), ou seja, a interatividade é quando a emissão e a recepção possibilitam a recriação da mensagem. Mensagem essa que não ficará mais restrita ao emissor, visto que esses dois elementos da comunicação se encontram. A "interatividade permite ultrapassar da condição de espectador passivo para a condição de sujeito operativo" (ALMEIDA, 2003, p. 2003).

A partir dessas ponderações, Marco Silva apresenta três princípios para a interatividade: a participação-intervenção, a qual permite a intervenção do receptor, visto que informação não é intangível, mas sim passível de recriação; a bidirecionalidade-hibridação, ou seja, o emissor pode assumir o papel de receptor e vice-versa. Esse princípio consiste na potencialidade de mudança de papéis dos agentes da comunicação, fato que permite a coautoria; e a permutabilidade-potencialidade, isto é, a comunicação presume várias redes associadas de conexões e iniciativas de trocas, agregando novos significados (SILVA, 2008).

Nesse sentido, com base nos estudos de Silva (2000), pode-se dizer que a interatividade permite ao expectador romper com a passividade e migrar para uma condição de sujeito ativo. Dessa maneira, é preciso garantir a intervenção do usuário no conteúdo da mensagem, proporcionando modificações, indicando a concretização da interatividade por meio da disposição interativa que permite ao usuário atuar e ser autor, cocriador do conteúdo da comunicação interativa. 


\section{METODOLOGIA}

A fim de compreender a proposta deste trabalho, apresenta-se a seguir o tipo de pesquisa e o detalhamento do procedimento de coleta e análise dos dados utilizados pelas pesquisadoras.

\subsection{Tipo de Pesquisa}

Esta pesquisa é qualiquantitativa. Ela é qualitativa devido à preocupação com os significados e motivações, um espaço profundo das relações. As pesquisas qualitativas "[...] podem descrever a complexidade de determinados problemas, analisar a interação de certas variáveis, compreender e classificar processos dinâmicos vividos por grupos sociais [...]" (RICHARDSON, 1989 p. 39).

Ademais, ela é quantitativa, pois visa à apresentação e ao manuseio numérico de observações com a finalidade de descrevê-las e explicá-las. Nesse sentido, Gil (2002) afirma que, na aplicação dos métodos quantitativos, utilizam-se frequentemente as estimativas numéricas e as inferências estatísticas obtidas a partir de uma amostra representativa de uma população real. O uso complementar de ambas as abordagens torna a pesquisa mais útil para o estudo do fenômeno discutido neste trabalho, pois:

Para sistematizar e solidificar as abordagens, nós utilizamos por vezes um raciocínio indutivo e outras vezes um método dedutivo, passando constantemente de uma abordagem à outra, elaborando hipóteses e estabelecendo comparações. (STRAUSS; CORBIN, 1992, p. 127 apud GIL, 2002, p. 84).

Por fim, é importante ressaltar que esta pesquisa integra-se a um grupo de estudos e pesquisas, o qual ofereceu uma formação continuada de professores, indígenas (da Aldeia Bananal, município de Aquidauana, MS) e não indígenas (de uma Universidade Privada), voltada às discussões sobre as tecnologias no contexto educacional, com foco na interconectividade, linguagem e colaboração.

\subsection{Procedimentos de Análise}

Para a realização da análise, fez-se necessário uma coleta de dados no grupo de professores presente no Facebook. Para isso, coletaram-se dados das postagens feitas pelos membros do grupo no decorrer do período de 08 meses, iniciando-se em 1 ㅇ de dezembro de 2015 até 31 de julho de 2016. Como instrumentos de análise, levou-se em consideração a data das postagens, bem como o autor, tipo de postagem, além do número de curtidas, comentários e visualizações que cada publicação recebeu. Vale salientar que a coleta dos dados feita no período referido pode variar a posteriori, visto que os números de curtidas, comentários e visualizações podem se alterar ao longo do tempo, pois os participantes têm livre acesso a todas as postagens feitas.

As postagens foram analisadas a partir de seu conteúdo, sendo organizadas em postagem do tipo texto, imagem e vídeo, com o intuito de verificar qual o tipo de publicação possui mais interatividade conforme o conceito de Primo (2000) sobre interação, e de Silva (2000), ou seja, qual o tipo de postagem possibilita a interatividade mútua, isto é, bidirecionalidade, participação e intervenção. As postagens do tipo texto possuíam apenas texto em seu conteúdo, as postagens do tipo imagem possuíam um pequeno texto e imagem, finalmente, as postagens do tipo vídeo possuíam um pequeno texto e vídeo. 
Para a coleta dos dados, primeiramente, contabilizou-se o total de postagens do tipo texto, depois imagem e, por fim, vídeo. Em seguida, determinou-se o total de curtidas, comentários e visualizações para cada um dos tipos de postagem.

Após a coleta dos dados, seguiu-se para análise deles. Foi feito uma análise da distribuição dos tipos de postagem, isto é, verificou-se a proporcionalidade entre a quantidade dos tipos de postagens, com o intuito de verificar qual tipo de postagem é mais feita e, comparando com os demais resultados, verificar se a estratégia de publicações é a mais efetiva para proporcionar a interatividade mútua.

Para fazer a comparação entre o número de curtidas, comentários e visualizações, calculou-se o valor médio destes em relação ao número de cada tipo de postagem $\left(I_{m}\right)$ por meio da

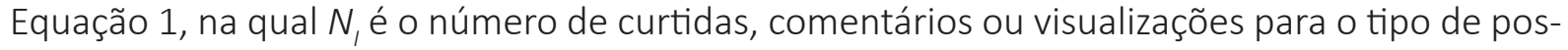
tagem analisada, e $N_{p}$ é o número de postagens do tipo analisada. Assim é possível comparar os valores obtidos mesmo para um número de publicações diferentes, determinando qual tipo de postagem é mais importante para alcançar a interatividade entre os membros do grupo.

$I_{m}=\frac{N_{I}}{N_{P}}$

Por fim, por meio das postagens feitas, foi possível analisar qual o conteúdo de cada postagem é mais relevante para os membros, deixando-os mais à vontade para participarem dos diálogos e discussões. Outro ponto analisado foi em relação à participação do(a) autor(a) de cada postagem, permitindo descrever os fluxos comunicacionais, investigando a participação dos integrantes nos processos interativos, isto é, se iniciam, continuam, problematizam e estabelecem novas conexões.

\section{RESULTADOS E ANÁLISES}

Nesta seção, apresentam-se os resultados e as análises qualiquantitativa dos dados obtidos nesta pesquisa, além das conclusões inferidas por eles. Porém, antes de apresentá-los, é fundamental descrever o raciocínio utilizado para construí-los. Inicialmente, foi contabilizado o total de postagens com apenas textos, imagens e vídeos ao longo dos meses estudados, conforme os resultados mostrados na Figura 1 .

Além disso, contabilizou-se o total de curtidas (Figura 1b), comentários (Figura 1c) e visualizações (Figura 1d). Dessa maneira, foi possível compreender a atividade dos membros do grupo. Notou-se que há uma oscilação tanto do número de postagens quanto do número de curtidas, comentários e visualizações. Ademais, foi possível relacionar diretamente a quantidade de postagens com o número de curtidas recebidas, isto é, o número de postagens é diretamente proporcional ao número de curtidas. Entretanto não é possível afirmar o mesmo para a quantidade de comentários recebidos; dessa maneira, pode-se concluir que os comentários estão diretamente relacionados com o conteúdo das postagens do que apenas da quantidade destas. A partir da descrição acima, apresenta-se a representação gráfica desse estudo na Figura 1. 


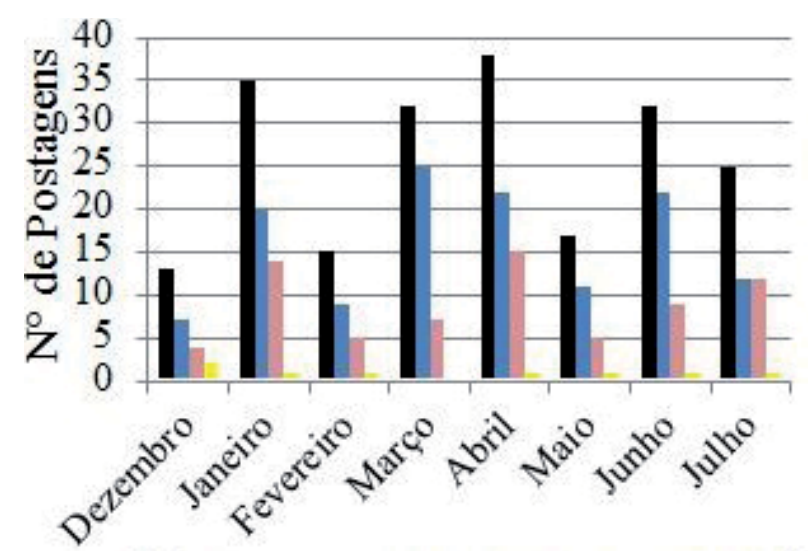

- Total de Postagens $\approx$ Texto $=$ Imagem $\approx$ Video

(a)

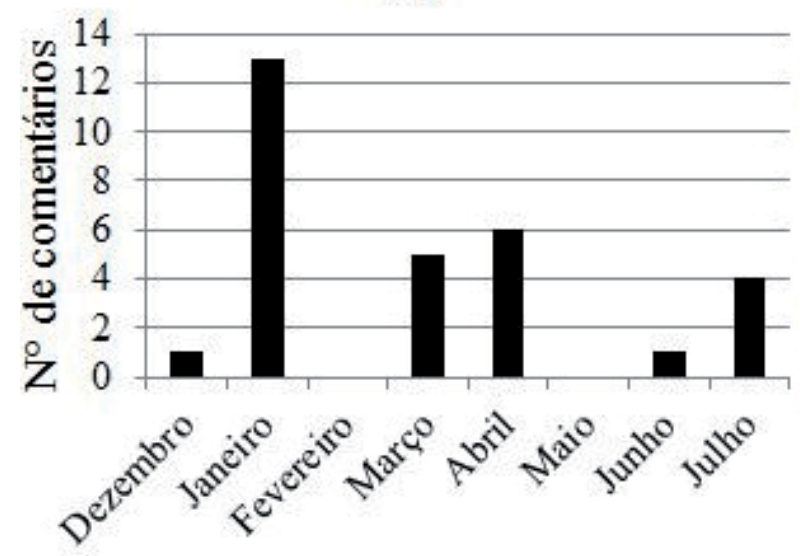

(c)

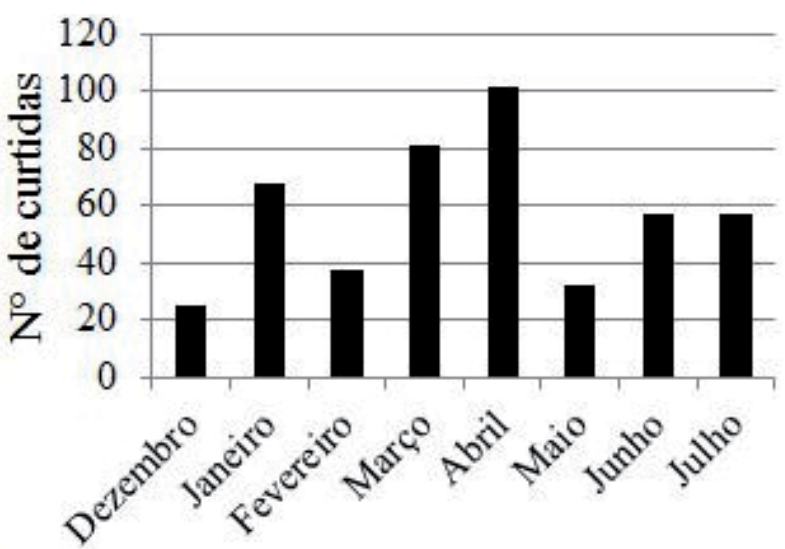

(b)

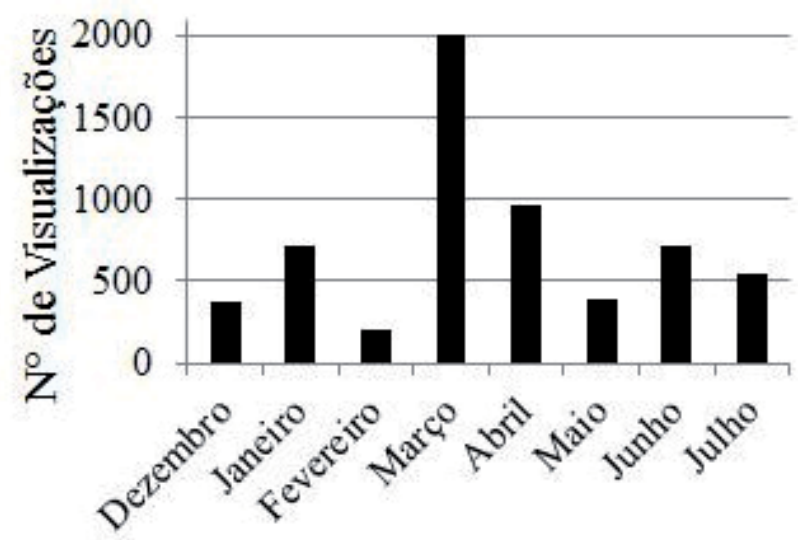

(d)

Figura 1 - Dados das postagens entre os meses de dezembro de 2015 a julho de 2016. (a) Distribuição mensal das postagens. (b) Distribuição mensal de curtidas. (c) Distribuição mensal dos comentários. (d) Distribuição mensal das visualizações.

Fonte: Elaborado pelos autores.

Em seguida, determinou-se o total de curtidas, comentários e visualizações para cada um dos tipos de postagem, conforme a Tabela 1.

Tabela 1 - Dados obtidos durante o período estudado.

\begin{tabular}{c|c|c|c|c}
\hline & Texto & Imagem & Vídeo & Total \\
\hline n. de postagem & 128 & 71 & 08 & 207 \\
\hline n. de curtidas & 239 & 205 & 14 & 458 \\
\hline n. de comentários & 05 & 25 & 00 & 30 \\
\hline n. de visualizações & 3.955 & 1.809 & 160 & 5924 \\
\hline
\end{tabular}

Fonte: Elaborado pelos autores.

Com base na Tabela 1, determinou-se a distribuição dos tipos de postagens feitas ao longo dos 08 meses estudados. Na Figura 2, a qual se encontra abaixo, é apresentada a distribuição total dos tipos de postagens feitas no grupo estudado. 


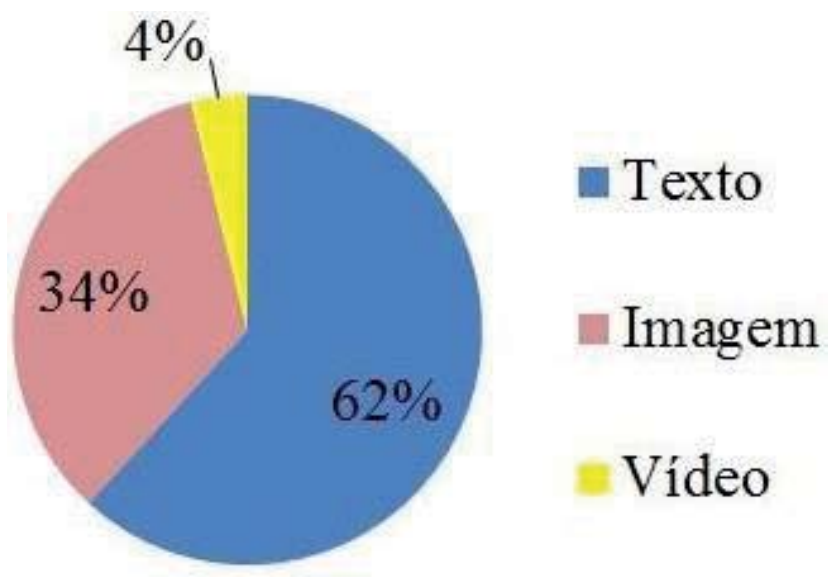

Figura 2 - Distribuição dos tipos de postagens durante os 8 meses estudados. Fonte: Elaborado pelos autores.

Em seguida, a partir dos dados da primeira tabela, foi possível determinar a média de distribuição de curtidas, comentários e visualização por postagem para cada tipo de conteúdo, isto é, postagens com texto, imagem e vídeo, conforme mostrado na Tabela 2.

Tabela 2 - Distribuição média de curtidas, comentários e visualizações por postagem.

\begin{tabular}{c|c|c|c}
\hline & Texto & Imagem & Vídeo \\
\hline Média de curtidas por postagens & 1,8672 & 2,8873 & 1,75 \\
\hline Média de comentários por postagens & 0,039 & 0,3521 & 00 \\
\hline Média de visualizações por postagens & 30,90 & 25,48 & 11,43 \\
\hline
\end{tabular}

Fonte: Elaborado pelos autores.

Com base na Tabela 2, nota-se que as postagens que em média mais recebem curtidas e comentários são as que têm imagem em seu conteúdo. Sendo assim, as imagens possibilitam uma interação mútua maior do que os textos. Tal fato justifica-se devido à recepção distinta que cada indivíduo tem em relação à imagem. Nesse sentido, Peter Loizos (2002, p. 141) afirma:

O "aprender" não é somente necessário para um reconhecimento básico, ele está também envolvido diferencialmente na percepção de detalhes significativos: um primeiro observador, olhando uma fotografia, vê um "carro"; um segundo vê uma "sala familiar de tamanho médio para pessoas idosas"; um terceiro vê um "Ford Cortina" do ano de 1981, com direção de corrida e de rodas de esporte". O veículo é o mesmo objeto do mundo real para todos os observadores, mas suas percepções, sua habilidade para especificá-lo e descrevê-lo, e o sentido que eles dão a ele são diferentes, devido a suas biografias individuais.

Outra consideração importante a fazer é em relação à média de visualizações. As postagens com apenas texto têm um número superior de visualizações comparado com as de apenas imagens. Entretanto, baseado no conceito de interatividade estudado neste trabalho, percebe-se que o ato de visualizar não estabelece o diálogo bidirecional, mas sim um caminho para ele.

Como mostrado na Figura 2, percebeu-se que, no período estudado, as postagens do tipo vídeo tiveram uma ocorrência muito menor que as demais, esse espaço amostral reduzido inviabilizou a comparação com os outros tipos de postagens. Sendo assim, as demais análises apresentadas levam em conta apenas as postagens do tipo texto e imagem. 
A partir da Tabela 2, foi possível estimar a quantidade de postagens de cada tipo para obter um comentário, instrumento que permite a interação mútua. Os valores indicam que são necessárias aproximadamente 26 postagens do tipo texto para a obtenção de um comentário, enquanto que, para a cada 03 postagens do tipo imagem, 1 comentário é feito. Sendo assim, as postagens que possuem imagens proporcionam a interatividade mútua entre os usuários.

Os resultados construídos mostraram que as postagens feitas no ambiente ainda estão aquém e buscam se aproximar dos conceitos de interação mútua (PRIMO, 2000) e interatividade (SILVA, 2000), de tal fato que se pode aumentar a interatividade aumentando a parcela de postagens do tipo imagem, já que essa mostrou necessitar de menos postagens para que houvesse a intervenção e participação entre os membros do grupo.

Vale-se salientar que, com base nos resultados expostos acima, não é possível inferir que não há interação e interatividade nesse grupo de professores, visto que apenas visualizar as postagens é um caminho para a interatividade. Nesse sentido, para Lévy (1999, p. 79) o termo interatividade:

[...] ressalta a participação ativa do beneficiário de uma transação de informação. De fato, seria mostrar que o receptor de informação, a menos que esteja morto, nunca é passivo. Mesmo sentado na frente de uma televisão sem controle remoto, o destinatário decodifica, interpreta, participa, mobiliza seu sistema nervoso de muitas maneiras, e sempre de forma diferente de seu vizinho.

\section{CONSIDERAÇÕES FINAIS}

A presente pesquisa objetivou analisar as possíveis interatividades entre professores em processo de formação continuada no contexto da rede social Facebook por meio das postagens realizadas no grupo de professores "Formação Continuada Tecnológica: Linguagens, Saberes e Interculturalidade". Para atender a esse objetivo, utilizou-se como auxílio os referenciais teóricos escolhidos e, a partir deles, construiu-se uma análise qualiquantitativa dos dados colhidos no grupo em questão.

De acordo com os resultados, inicia-se a ideia de que, para a realização da interatividade no contexto da rede social Facebook, é necessário usar mais imagens como conteúdo de postagens. Tal conclusão vem do fato de que a interação mútua e a interatividade plena podem ocorrer por meio dos comentários nas postagens, visto que as publicações cujo conteúdo era imagem incentivaram uma participação-intervenção maior do que aquelas que apresentavam textos em seu conteúdo. Vale lembrar que as postagens com vídeo em seu conteúdo não foram tomadas em conta devido ao pequeno número dessas postagens em relação às com imagem e texto.

Além disso, tal análise possibilitou o surgimento de novos questionamentos sobre a interatividade, por exemplo, como ela se dá sem a participação direta dos membros do grupo? como se dá a relação dos participantes? isso permite às pessoas que desejam trabalhar com essa temática construir novas possiblidades e questionamentos.

Por fim, as propostas de formação continuada de professores devem ser voltadas para problematizar, refletir e partilhar conhecimentos. Uma formação para todos os cidadãos, crítica e comprometida com a emancipação humana. E, vale problematizar quando isto acontece no meio de uma sociedade intitulada "digital", em que comunicações, discussões, diálogos e trocas ocorrem por meio das tecnologias de informação e comunicação, como por exemplo, por meio de redes sociais. Sendo assim, é fundamental compreender como essas trocas se dão nesses ambientes para que seja possível buscar estratégias que fomentem sua realização. 


\section{REFERÊNCIAS}

ALMEIDA, Maria Elizabeth Bianconcini. Educação, ambientes virtuais e interatividade. In: SILVA, Marco (Org.). Educação online: teorias, práticas, legislação, formação corporativa. São Paulo: Loyola, 2003. p. 201-15.

Informática e formação de professores. Brasília: MEC/SEED, 2000. v. 1.

BAIRRAL, Marcelo Almeida. Discurso, interação e aprendizagem da Matemática em ambientes virtuais à distância. Seropédica, RJ: Editora Universidade Rio de Janeiro, 2007.

BRITO, Gláucia da Silva; PURIFICAÇÃO, Ivonélia da. Educação e novas tecnologias um re-pensar. 2. ed. Curitiba: Ibpex, 2008.

LOIZOS, Peter. Vídeo, filme e fotografias como documentos de pesquisa. In: BAUER, Martin W.; GASKELL, George (Org.). Pesquisa qualitativa com texto: imagem e som- um manual prático. Rio de Janeiro: Vozes, 2002. p. 137-55.

GIL, Antonio Carlos. Como elaborar um projeto de pesquisa. 4. ed. São Paulo: Atlas, 2002.

KENSKI, Vani Moreira. Tecnologias e ensino presencial e a distância. Campinas, São Paulo: Papirus, 2003. LÉVY, Pierri. Cibercultura. São Paulo: Editora 34, 1999.

PRIMO, A. Interação mútua e reativa: uma proposta de estudo. Revista da Famecos, n. 12, p. 81-92, jun. 2000.

RICHARDSON, Roberto Jarry. Pesquisa social: métodos e técnicas. 2. ed. São Paulo: Atlas, 1989.

SILVA, Marco. Cibercultura e educação: a comunicação na sala de aula presencial e online. Revista FAMECOS: mídia, cultura e tecnologia, Porto Alegre, v. 15, n. 37, 2008. Disponível em: <http://revistaseletronicas. pucrs.br/ojs/index.php/revistafamecos/article/view/4802>. Acesso em: 16 jul. 2016.

SILVA, Marco. Que é interatividade. Rio de Janeiro: Editora Senac, 1998.

Sala de Aula Interativa. Rio de Janeiro: Quartet, 2000.

VALENTE, J. A. (Org.). O computador na sociedade do conhecimento. Campinas, SP: NIED/Unicamp, 1999.

\section{Sobre as autoras:}

Ana Paula Simões Pessoa: Graduada em Letras pela Universidade Católica Dom Bosco (UCDB). Foi bolsista CNPq no Programa Institucional de Bolsa de Iniciação Científica no projeto de pesquisa Cultura Digital em Uma Universidade Intercultural: Relações entre Tecnologias, Professores e Alunos (UCDB). É integrante do Grupo de Estudos e Pesquisas sobre Tecnologia Educacional e Educação a Distância (GETED). Mestranda em Linguística Aplicada da Universidade Estadual de Mato Grosso do Sul (UEMS). E-mail: anapaulasimoesz@gmail.com

Maria Cristina Lima Paniago: Graduada em Letras pela Faculdades Unidas Católicas de Mato Grosso (FUCMT), mestrado e doutorado em Linguística Aplicada e Estudos da Linguagem pela Pontifícia Universidade Católica de São Paulo. Pesquisadora visitante da Universidade de Manitoba, Canadá (Estágio Pós-Doutoral) Department of Family Social Science- Faculty of Human Ecology. Atualmente é professora do Programa de Pós-Graduação em Educação Mestrado e Doutorado na Universidade Católica Dom Bosco (UCDB). E-mail: cristina@ucdb.br 